\title{
A New Reversible Phase Transformation of Intermetallic $\mathrm{Ti}_{3} \mathrm{Sn}$
}

\author{
Minshu Du ${ }^{1,2, *(\mathbb{D})}$, Lishan Cui ${ }^{2}$ and Feng Liu ${ }^{1}$ \\ 1 School of Materials Science and Engineering, Northwestern Polytechnical University, Xi'an 710072, China \\ 2 State Key Laboratory of Heavy Oil Processing, China University of Petroleum, Beijing 102249, China \\ * Correspondence: minshudu@nwpu.edu.cn
}

Received: 3 July 2019; Accepted: 2 August 2019; Published: 5 August 2019

\begin{abstract}
Ti}_{3} \mathrm{Sn}$ has received increasing attention as a high damping metallic material and as an anode material for rechargeable lithium-ion batteries. However, a heated dispute concerning the existence of solid state phase transformation of stoichiometric $\mathrm{Ti}_{3} \mathrm{Sn}$ impedes its development. Here, thermal-induced reversible phase transformation of $\mathrm{Ti}_{3} \mathrm{Sn}$ is demonstrated to happen at around $300 \mathrm{~K}$ by the means of in-situ variable-temperature $\mathrm{X}$-ray diffraction (XRD) of $\mathrm{Ti}_{3} \mathrm{Sn}$ powder, which is also visible for bulk $\mathrm{Ti}_{3} \mathrm{Sn}$ on the thermal expansion curve by a turning at $330 \mathrm{~K}$. The new phase's crystal structure of $\mathrm{Ti}_{3} \mathrm{Sn}$ is determined to be orthorhombic with a space group of $\mathrm{Cmcm}$ and the lattice parameters of $\mathrm{a}=5.87 \AA, \mathrm{b}=10.37 \AA, \mathrm{c}=4.76 \AA$ respectively, according to selected area electron diffraction patterns in transmission electron microscope (TEM) and XRD profiles. The hexagonal $\rightarrow$ orthorhombic phase transformation is calculated to be reasonable and consistent with thermodynamics theory. This work contributes to a growing knowledge of intermetallic $\mathrm{Ti}_{3} \mathrm{Sn}$, which may provide fundamental insights into its damping mechanism.
\end{abstract}

Keywords: $\mathrm{Ti}_{3} \mathrm{Sn}$; phase transformation; crystal structure; X-ray diffraction; transmission electron microscopy

\section{Introduction}

There are increasing attempts focusing on Sn-based anode materials for rechargeable lithium-ion batteries due to their high storage capacities [1-4], among which the intermetallic $\mathrm{Ti}_{3} \mathrm{Sn}$ seems to be the representative one $[5,6]$. $\mathrm{Ti}_{3} \mathrm{Sn}$ has received attention due to its ultra-high mechanical damping property in the wide frequency range of $1-200 \mathrm{~Hz}$ as well as $20-100 \mathrm{KHz}$ [7], which is promising for energy dissipation applications such as vibration-resistant components and noise-cancelling products. The damping capacity $\mathrm{Q}^{-1}$ of $\mathrm{Ti}_{3} \mathrm{Sn}$ is almost one order of magnitude higher than that of commercial damping alloys including grey cast iron, $\mathrm{Fe}-\mathrm{Mn}, \mathrm{Ni}-\mathrm{Ti}, \mathrm{Sn}-\mathrm{Pb}$ alloys, etc. [7,8]. The results of dynamic mechanical analysis (DMA) of $\mathrm{Ti}_{3} \mathrm{Sn}$ with a frequency of $1 \mathrm{~Hz}$ measured under heating reveal the interesting points: an obvious damping peak exists at about $310 \mathrm{~K}$ which just corresponds to the turning point of storage modulus; when the temperature is lower than $310 \mathrm{~K}$, the damping capacity increases continuously [7]. Though the basic damping mechanism of $\mathrm{Ti}_{3} \mathrm{Sn}$ remains unknown presently, these experimental data suggest the appearance of a phase transformation in $\mathrm{Ti}_{3} \mathrm{Sn}$ at near-room temperature ( $310 \mathrm{~K})$.

According to the Ti-Sn equilibrium diagram [9], $\mathrm{Ti}_{3} \mathrm{Sn}$ melts congruently at $1943 \mathrm{~K}$, and it remains stable down to room temperature without undergoing any phase transformations. The intermetallics has the ordered hexagonal $\mathrm{D}_{19}$ crystal structure with a space group of $\mathrm{P} 6_{3} / \mathrm{mmc}$ (No. 194) and the lattice parameters of $\mathrm{a}=5.916 \pm 0.004 \AA$ and $\mathrm{c}=4.764 \pm 0.004 \AA$ [10]. Colin McCullough et al. in 1993 studied the phase selection in undercooled $\mathrm{Ti}_{3} \mathrm{Sn}$ melts, and reported two previously unknown metastable forms of $\mathrm{Ti}_{3} \mathrm{Sn}$ : base-centered orthorhombic structure (space group: $\mathrm{C}_{\mathrm{mmm}}$ ) with the lattice parameters 
of $\mathrm{a}=9.76 \AA \mathrm{b}=6.18 \AA$ and $\mathrm{c}=4.75 \AA$ in the sample with supercoolings of $109 \mathrm{~K}$ and $311 \mathrm{~K}$; monoclinic structure with the lattice parameters of $a=5.72 \AA, b=4.74 \AA, c=6.05 \AA$ and $\beta=79.5^{\circ}$ in the sample with supercoolings of $258 \mathrm{~K}$ [11]. Ivanova, et al. has reported a reversible group-subgroup transformation between $\mathrm{D0}_{19}$ phase and new orthorhombic phase of non-stoichiometric $\mathrm{Ti}_{3} \mathrm{Sn}\left(\mathrm{Ti}_{75.5} \mathrm{Sn}_{24.5}\right)$ [12]. However, no new equilibrium structure of stoichiometric $\mathrm{Ti}_{3} \mathrm{Sn}$ has been reported. Even though the existence of equilibrium phase transformation of $\mathrm{Ti}_{3} \mathrm{Sn}$ has been discovered indirectly from its DMA results in [7], there are no direct experimental data about it, and the characteristics of transformation and crystal structure of new phase still remain unknown.

In this paper, by the means of thermal expansion measurement and in-situ X-ray diffraction during cooling/heating, thermal-induced reversible transformation of $\mathrm{Ti}_{3} \mathrm{Sn}$ was observed directly, and the crystal structure of the new phase was determined based on a set of electron diffraction patterns in TEM and XRD profiles. The results could provide fundamental insights into the properties of $\mathrm{Ti}_{3} \mathrm{Sn}$ in the application as the anode material of lithium-ion battery, since volume change and phase transformation during lithiation and delithiation process at different temperatures should be carefully considered, which may lead to the low storage capacity, poor cycling and even the cracking and crumbing of the metal electrode $[13,14]$. In addition, it is helpful to decode the mechanical damping mechanism of $\mathrm{Ti}_{3} \mathrm{Sn}$ and improve the development of $\mathrm{Ti}_{3} \mathrm{Sn}$ as a new generation of high damping metallic materials.

\section{Experimental Section}

\subsection{Preparation of Samples}

High-purity stoichiometric $\mathrm{Ti}_{3} \mathrm{Sn}$ intermetallic ingot with a nominal composition of $\mathrm{Ti}_{75} \mathrm{Sn}_{25}$ (atomic percent) was prepared by arc melting in a water-cooled copper crucible using $99.99 \%$ (atomic percent) purity starting elements. The ingot was melted eight times repeatedly and then homogenized under vacuum in a furnace at $1223 \mathrm{~K}$ for $10 \mathrm{~h}$. There were two kinds of specimens used in our experiments: the bulk $\mathrm{Ti}_{3} \mathrm{Sn}$ samples were taken from the ingot with proper size by electric discharge machining, and the $\mathrm{Ti}_{3} \mathrm{Sn}$ ultrafine powders (with particle size of $\sim 50 \mu \mathrm{m}$ ) which were obtained by grinding the bulk material in an agate mortar for $30 \mathrm{~min}$ and annealing at $673 \mathrm{~K}$ for $20 \mathrm{~min}$ under vacuum in a furnace in order to eliminate the residual stress that generated during the milling process.

\subsection{DSC and Thermal Expansion Measurement}

Differential scanning calorimetry (DSC) test was carried out on the NETZSCH 204 F1 using bulk sample in the $\mathrm{Al}_{2} \mathrm{O}_{3}$ crucible, and the heating/cooling rate was $10^{\circ} \mathrm{C} / \mathrm{min}$ in the argon atmosphere. Thermal expansion measurement was carried out on the WRP-1 equipment with a heating/cooling rate of $10^{\circ} \mathrm{C} / \mathrm{min}$. The sample size for thermal expansion test was $25 \mathrm{~mm} \times 2 \mathrm{~mm} \times 1 \mathrm{~mm}$ according to ASTM (American society for testing and materials) standards.

\subsection{Transmission Electron Microscopy (TEM) Characterization}

The sample for transmission electron microscopy (TEM) characterization was prepared by mechanical grinding, dimpling and ion milling, successively. TEM observations were carried out with a JEM-2100 microscope (JEOL, Tokyo, Japan) operated at a voltage of $200 \mathrm{kV}$. A Gatan K2 direct detection CCD camera (Gatan, Pleasanton, CA, USA) was used for image acquisition. It should be noted that the grain size of the as-cast $\mathrm{Ti}_{3} \mathrm{Sn}$ sample was in the range of hundreds of micrometers, and therefore the specimens fabricated for TEM observation were most likely to be from a single grain. The crystal structure of a new phase of $\mathrm{Ti}_{3} \mathrm{Sn}$ was determined based on a series of selected area electron diffraction (SAED) patterns. The reflection conditions were summarized according to SAED, which was then indexed to new phase structure parameters. Space group could also be uniquely determined based on reflection conditions. 


\subsection{XRD Analysis}

In-situ X-ray diffraction (XRD) measurements during cooling process $(320 \mathrm{~K} \rightarrow 93 \mathrm{~K})$ and heating process ( $93 \mathrm{~K} \rightarrow 320 \mathrm{~K}$ ) were carried out on a Bruker AXS D8 equipment (Bruker, Karlsruhe, Germany) using $\mathrm{Cu} \mathrm{K} \alpha$ radiation with a wavelength of $1.54056 \AA$ under a scanning rate of $2^{\circ} / \mathrm{min}$. Ni-plated copper sample holder was fixed on the cooling or heating block. The cooling block was cooled by a continuous liquid nitrogen flow, and the heating block contained a heating strip made of $\mathrm{AlCr}$. The new phase's crystal structure was also solved using JADE (6.5 version, Livermore, CA, United States) and Jana software (2006 version, Praha, Czech Republic).

\subsection{First Principle Calculation}

The formation enthalpy of $\mathrm{Ti}_{3} \mathrm{Sn}$ was calculated using density functional theory (DFT) implemented in the Vienna Ab initio Simulation Package (VASP) with standard potential function [15-17]. All the structures were fully relaxed with respect to volume and the atomic coordinates. A cutoff of $360 \mathrm{eV}$ was used for all elements. The settings of k-points correspond roughly to a $5000 \mathrm{k}$-point mesh per reciprocal atom. The formation enthalpy (with thermal contributions and zero-vibration energy difference or contribution being ignored) for an equilibrium phase $\mathrm{Ti}_{\mathrm{x}} \mathrm{Sn}_{\mathrm{y}}$ can be defined as $[18,19]$ :

$$
\Delta \mathrm{H}\left(\mathrm{Ti}_{\mathrm{x}} \mathrm{Sn}_{\mathrm{y}}\right)=\mathrm{E}\left(\mathrm{Ti}_{\mathrm{x}} \mathrm{Sn}_{\mathrm{y}}\right)-\mathrm{x}_{\mathrm{Ti}} \cdot \mathrm{E}(\mathrm{Ti})-\mathrm{y}_{\mathrm{Sn}} \cdot \mathrm{E}(\mathrm{Sn})
$$

where $\mathrm{E}\left(\mathrm{Ti}_{\mathrm{x}} \mathrm{Sn}_{\mathrm{y}}\right)$ is the total energy of $\mathrm{Ti}_{\mathrm{x}} \mathrm{Sn}_{\mathrm{y}}$ phase per atom, obtained by first-principle calculations. $\mathrm{E}(\mathrm{Ti})$ and $\mathrm{E}(\mathrm{Sn})$ are the energy for the pure elements Ti and Sn, respectively. $\mathrm{x}_{\mathrm{Ti}}=\mathrm{x} \backslash(\mathrm{x}+\mathrm{y})$ and $\mathrm{y}_{\mathrm{Sn}}=$ $\mathrm{y} \backslash(\mathrm{x}+\mathrm{y})$ are the fractional compositions of Ti and Sn, respectively.

\section{Results and Discussion}

\subsection{Detection and Characterization of Phase Transformation of $\mathrm{Ti}_{3} \mathrm{Sn}$}

At the beginning, conventional methods of DSC and thermal expansion tests were used to detect the phase transformation of $\mathrm{Ti}_{3} \mathrm{Sn}$. DSC result in Figure 1a shows a wide and weak endothermic peak at about $330 \mathrm{~K}$ during heating process, and the corresponding exothermic peak during cooling process was too weak to be clearly observed. The thermal expansion measurement result in Figure $1 \mathrm{~b}$ shows an obvious turning at about $330 \mathrm{~K}$, which means the thermal expansion coefficient of $\mathrm{Ti}_{3} \mathrm{Sn}$ changes at this temperature. It is quite possible that the solid state phase transformation of intermetallic $\mathrm{Ti}_{3} \mathrm{Sn}$ indeed exhibits at room temperature ( $\sim 330 \mathrm{~K}$ from thermal expansion test result) as suggested by DMA results in [7].
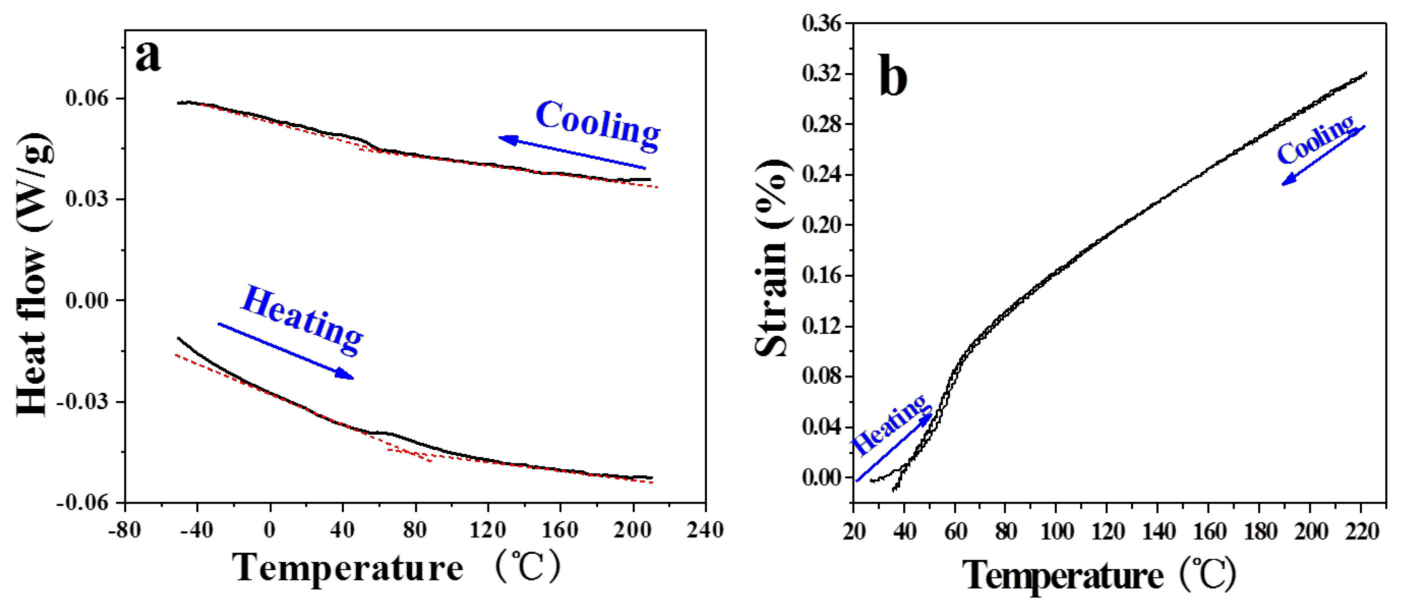

Figure 1. Phase transformation characterization of intermetallic $\mathrm{Ti}_{3} \mathrm{Sn}$. (a) DSC result. (b) Thermal expansion test result. 
In order to characterize the phase transformation directly, in-situ XRD experiments of both bulk $\mathrm{Ti}_{3} \mathrm{Sn}$ sample and $\mathrm{Ti}_{3} \mathrm{Sn}$ ultrafine powder were carried out during cooling process. It is true that the crystal structure of $\mathrm{Ti}_{3} \mathrm{Sn}$ at $320 \mathrm{~K}$ is ordered as a hexagonal $\mathrm{D0}_{19}$ structure with the lattice parameters as shown in [10]. However, entirely different XRD patterns of two kinds of $\mathrm{Ti}_{3} \mathrm{Sn}$ samples have been obtained during cooling process from $320 \mathrm{~K}$ down to $93 \mathrm{~K}$. For bulk $\mathrm{Ti}_{3} \mathrm{Sn}$, Figure 2 a reveals no shape changes of hexagonal $\mathrm{D0}_{19}$ structural diffraction peaks (002), (201), and (203), and the peak positions are almost the same. While for $\mathrm{Ti}_{3} \mathrm{Sn}$ powder, Figure $2 \mathrm{~b}$ reveals that $\mathrm{D}_{19}(002)$ peak at about $37.8^{\circ}$ at $320 \mathrm{~K}$ moves toward high diffraction angle direction gradually during cooling and changes to be at about $37.9^{\circ}$ at $93 \mathrm{~K} ; \mathrm{D0}_{19}(201)$ peak around $39.9^{\circ}$ at $320 \mathrm{~K}$ splits to two new peaks at $39.5^{\circ}$ and $40.3^{\circ}$ at $93 \mathrm{~K} ; \mathrm{D0}_{19}$ (203) peak at $69.6^{\circ}$ at $320 \mathrm{~K}$ also splits into two new peaks at $69.4^{\circ}$ and $70.1^{\circ}$ respectively at $93 \mathrm{~K}$ during cooling process. It is known that diffraction peaks splitting and new peaks appearing are the proofs of symmetry-breaking phase transformation. As a result, we present the direct evidence of solid state phase transformation of $\mathrm{Ti}_{3} \mathrm{Sn}$. By comparison, the XRD peaks of bulk $\mathrm{Ti}_{3} \mathrm{Sn}$ sample (with grain size of about $400 \mu \mathrm{m}$ ) are quite wider than that of $\mathrm{Ti}_{3} \mathrm{Sn}$ ultrafine powders (with particle size of $\sim 50 \mu \mathrm{m}$ as measured by SEM). The abnormal broadening of XRD peaks of bulk $\mathrm{Ti}_{3} \mathrm{Sn}$ was not fully understood, and it was speculated to be mainly caused by strain/stress generated from the overlapping nano-twins [20]. As shown in Figure 3, there are a mass of nano-twins in bulk $\mathrm{Ti}_{3} \mathrm{Sn}$ in the form of stepped twins, lamellar twins and polygon twins, the overlap and intersection of which would probably cause large strain or stress within the grain and result in XRD peak broadening. In addition, it is noted that the $\mathrm{D0}_{19}$ (201) peak existed during the cooling process till $93 \mathrm{~K}$ (shown in Figure 2b, middle subfigure), the area of which decreased gradually along with the area increases of two new phase's peaks during cooling. Thus, it is indicated that phase transformation of $\mathrm{Ti}_{3} \mathrm{Sn}$ kept going during 310-93 K cooling process and did not complete leaving with a certain amount of hexagonal parent phase at $93 \mathrm{~K}$. Such on-going phase transformation during cooling might be related to the continuously high damping $\left(\mathrm{Q}^{-1} \approx 0.2\right)$ of $\mathrm{Ti}_{3}$ Sn below $300 \mathrm{~K}$, as shown in Figure 4a in [7].
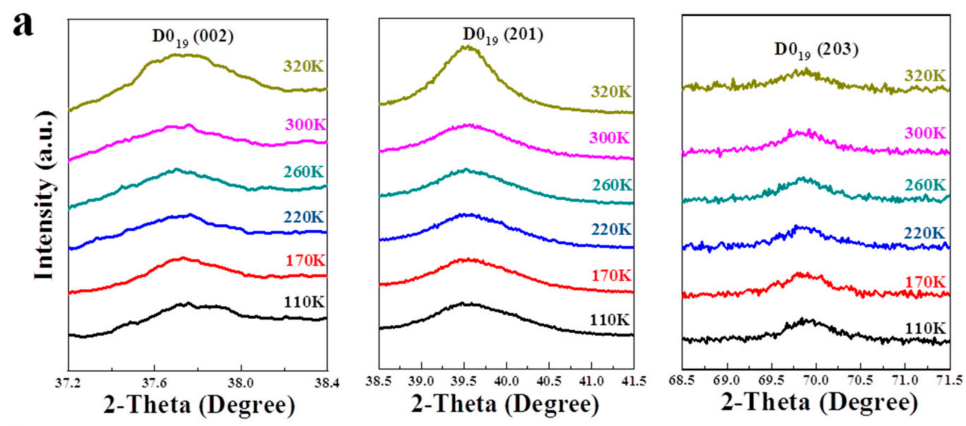

b

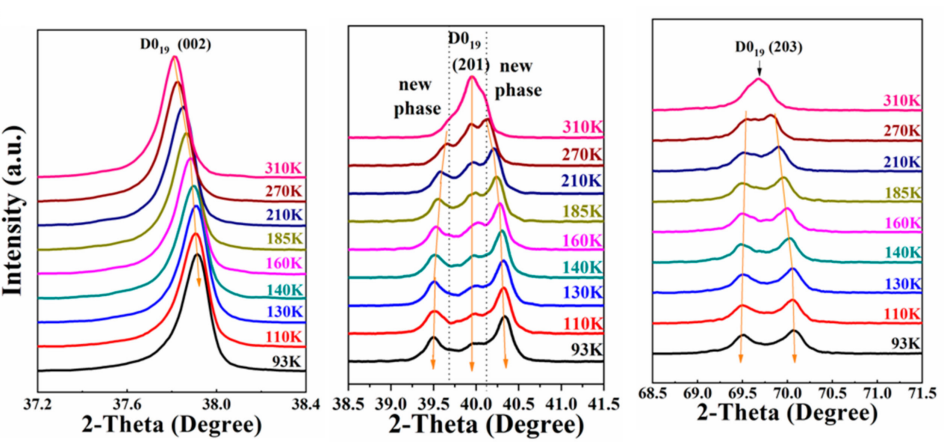

Figure 2. Comparison of conventional X-ray diffraction (XRD) patterns between (a) bulk $\mathrm{Ti}_{3} \mathrm{Sn}$ sample and (b) $\mathrm{Ti}_{3} \mathrm{Sn}$ powder during the cooling process. (a) XRD peaks of bulk $\mathrm{Ti}_{3} \mathrm{Sn}$ near hexagonal $\mathrm{D}_{19}$ phase (002), (201) and (203) crystal faces. (b) XRD peaks of $\mathrm{Ti}_{3} S \mathrm{Sn}$ powder near hexagonal $\mathrm{D}_{19}$ phase (002), (201) and (203) crystal faces, respectively. 

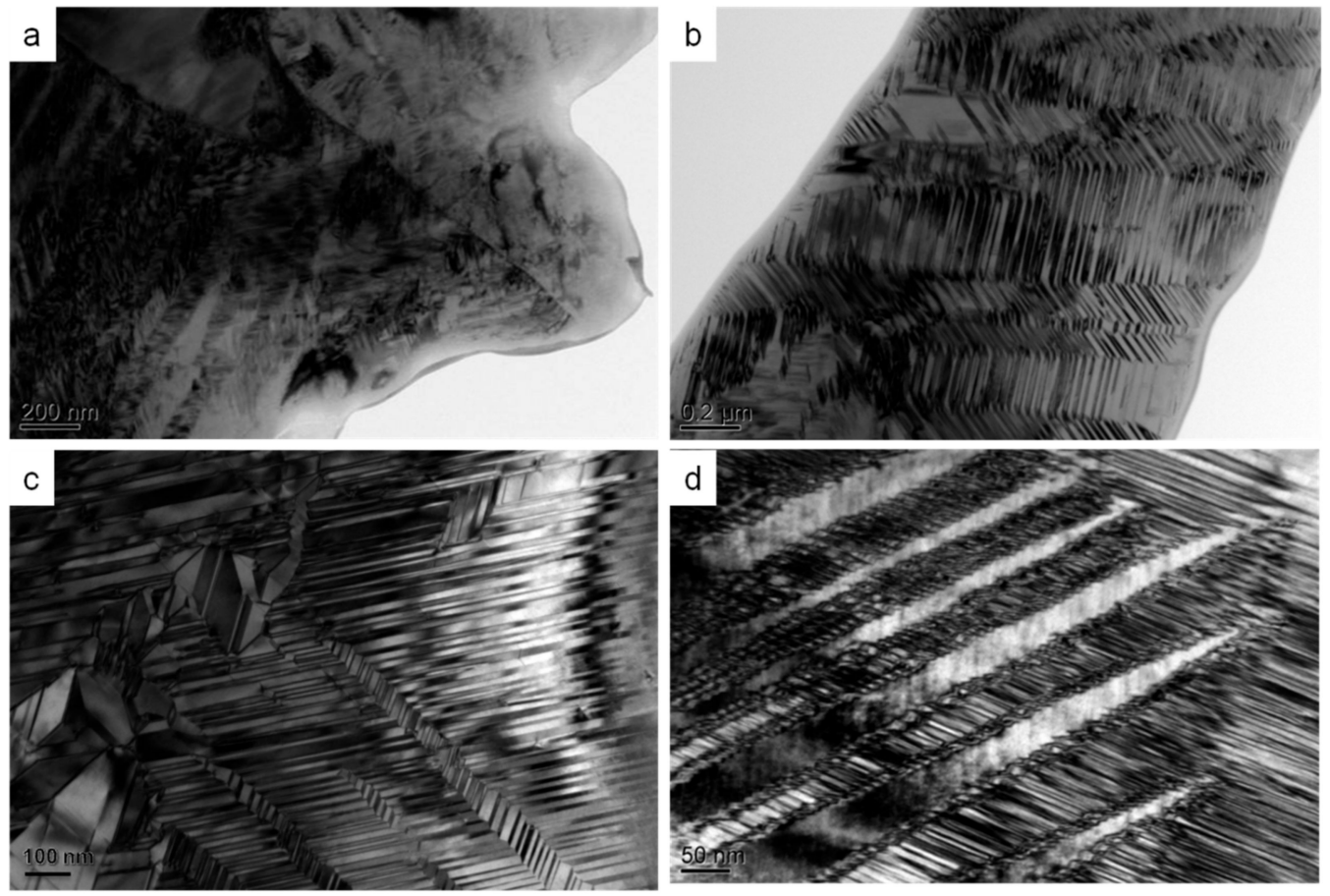

Figure 3. Overlapping twins in bulk $\mathrm{Ti}_{3} \mathrm{Sn}$ sample. (a) Extensively distributed twins; (b) lamellar nano-twins; (c) multiple twins distributed with $120^{\circ}$ crossover; (d) stepped twins and inner lamellar twins.
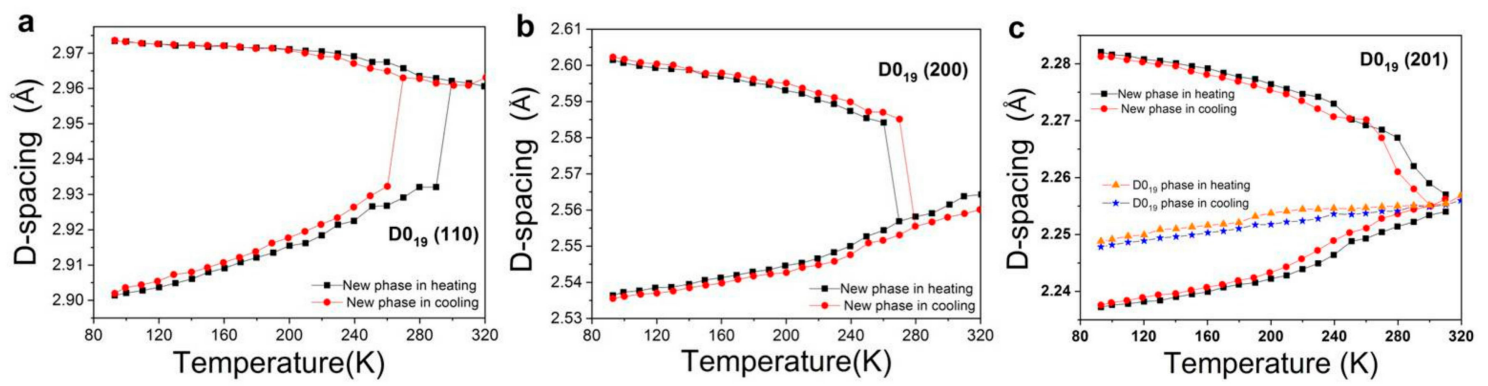

Figure 4. Lattice d-spacing variations of $\mathrm{Ti}_{3} \mathrm{Sn}$ powder during in-situ cooling and heating process. (a) D-spacing change of $\mathrm{DO}_{19}$-(110) plane; (b) d-spacing change of $\mathrm{D0}_{19}-(200)$ plane; (c) d-spacing change of $\mathrm{D}_{19}$-(201) plane in a temperature range of 93-320 K, respectively. The $\mathrm{D}_{19}$ (201) peak still existed after phase transformation to the lowest temperature of $93 \mathrm{~K}$.

Lattice d-spacing changes of (110), (200) and (201) peaks of powder $\mathrm{Ti}_{3} S \mathrm{Sn}$ hexagonal $\mathrm{D}_{19}$ phase during in-situ cooling and heating processes were indicated in Figure 4 respectively, in which the d-spacing value was calculated according to Bragg equation of: $2 d \times \sin \theta=n \lambda$ on the basis of a set of $\mathrm{Ti}_{3} \mathrm{Sn}$ powder XRD profiles. From Figure 4, D0 19 (110), (200) and (201) planes show obvious peak splitting into two new peaks during cooling from $320 \mathrm{~K}$ to about $93 \mathrm{~K}$, while two new peaks also merge to the original $\mathrm{D}_{19}$ peak during the following heating process. Thus, this symmetry-breaking phase transformation of $\mathrm{Ti}_{3} \mathrm{Sn}$ is proved to be reversible with a hysteresis of 10-30 K. For example, as shown in Figure $4 \mathrm{a}$, lattice d-space of $\mathrm{D0}_{19}(110)$ at the temperature higher than room temperature $(\sim 300 \mathrm{~K})$ is about $2.96 \AA$ and splits into two new peaks at $270 \mathrm{~K}$, d-spacing of one new peak increases and d-spacing of the other peak decreases as the temperature further goes down. It is noted that d-spacing increases during cooling indicating a negative thermal expansion (NET) of $\mathrm{Ti}_{3} \mathrm{Sn}$ in a certain temperature range. NET is generally known and occurs in zeolites, metal oxides, Aluminum phosphates, and so on [21,22]. The origin and mechanism for $\mathrm{NET}$ in $\mathrm{Ti}_{3} \mathrm{Sn}$ is currently unknown and needs to be studied in the future. 


\subsection{Crystal Structure of a New Phase of $\mathrm{Ti}_{3} \mathrm{Sn}$}

Two methods were employed to solve the crystal structure of the new phase of $\mathrm{Ti}_{3} \mathrm{Sn}$. The first method for determining the crystal system and space group was based on SAED patterns of TEM. For $\mathrm{Ti}_{3} \mathrm{Sn}$ bulk sample, the phase transformation started at $\sim 310 \mathrm{~K}$ from the previous DMA result [7] or $\sim 330 \mathrm{~K}$ from our thermal expansion measurement result. Thus we can determine the new phase's crystal structure of $\mathrm{Ti}_{3} \mathrm{Sn}$ foil specimen at room temperature $(\sim 290 \mathrm{~K})$ by the traditional selected area electron diffraction technique of TEM. By systematically tilting the $\mathrm{Ti}_{3} \mathrm{Sn}$ specimen, a set of SAED patterns were obtained as shown in Figure 5. The crystal zone axis and experimental tilting angle between the neighboring SAED patterns are noted in the figure. Analyzing the patterns, the reflection conditions could be obtained as: for $h k l, h+k=2 n$; for $0 k l, k=2 n$; for $h 01, h, l=2 n$; for $h k 0, h+k=2 n$; $\mathrm{h} 00, \mathrm{~h}=2 \mathrm{n}$; for $0 \mathrm{k} 0, \mathrm{k}=2 \mathrm{n}$; for $001,1=2 \mathrm{n}$. Thus, the reflections can be indexed according to a base-centered orthorhombic structure with lattice parameters of $\mathrm{a}=6.10 \AA, \mathrm{b}=10.45 \AA, \mathrm{c}=4.89 \AA$, and the space group was uniquely determined to be $\mathrm{Cmcm}$ (No. 63) according to the International Tables for Crystallography [23].

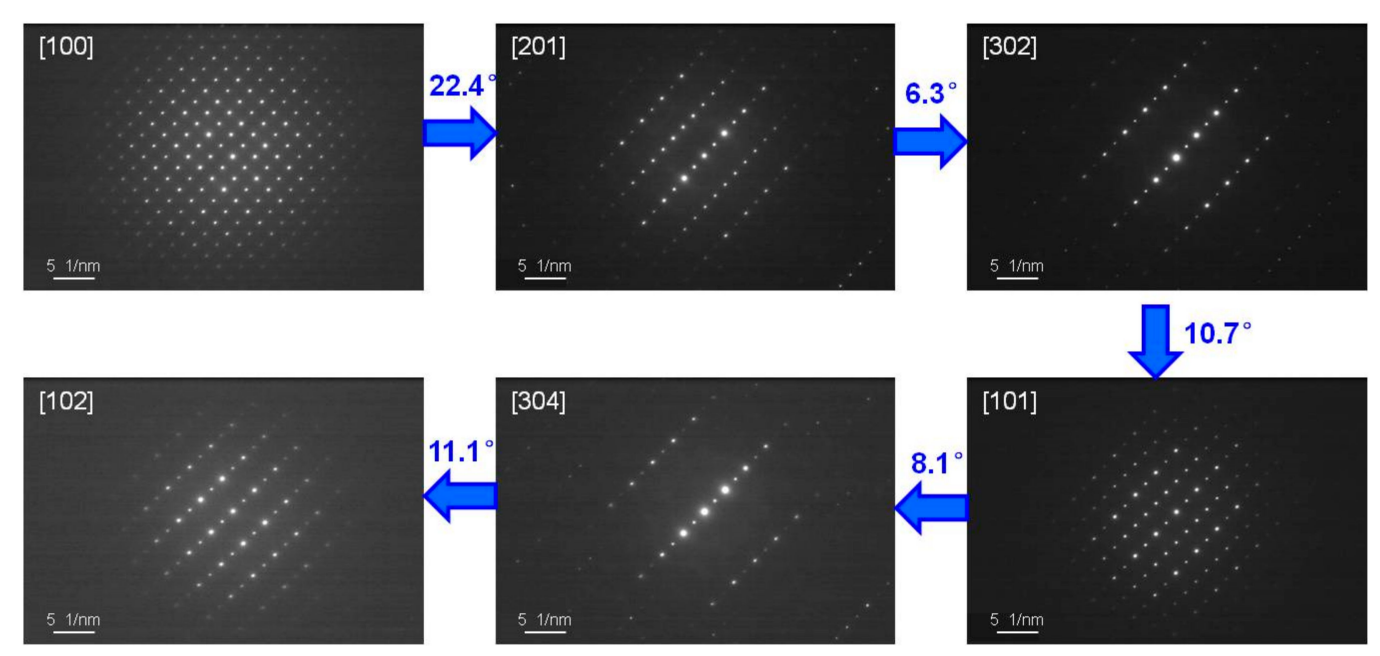

Figure 5. A set of selected area electron diffraction (SAED) patterns of $\mathrm{Ti}_{3} \mathrm{Sn}$ at the room temperature. The crystal zone axis and experimental tilting angle between the neighboring SAED patterns are indicated in the figure.

It is known that the accuracies of the measured d-values and the angles between the reflections of SAED are inferior to the accuracy in X-ray diffraction (XRD) due to the presence of electromagnetic lenses in the TEM [24]. Thus, crystal structure of the new phase of $\mathrm{Ti}_{3} \mathrm{Sn}$ was further determined from XRD profiles of $\mathrm{Ti}_{3} \mathrm{Sn}$ powder (shown in Figure $2 \mathrm{~b}$ ) using JADE and Jana software after Rietveld full-profile refinement. The refinement result of XRD profile of $\mathrm{Ti}_{3} \mathrm{Sn}$ powder at $93 \mathrm{~K}$ was shown in Figure 6, in which the hexagonal phase and the orthorhombic phase positions were indicated by green bars and red bars, respectively. Phase content could also be obtained, which turned out the existence of $17.34 \%$ parent phase (hexagonal phase) left without transformation at $93 \mathrm{~K}$. XRD profile at $93 \mathrm{~K}$ was indexed to be base-centered orthorhombic structure with lattice parameters of $a=5.87 \AA, b=10.37 \AA$, $\mathrm{c}=4.76 \AA$, and the space group was $\mathrm{Cmcm}$, atomic Wyckoff positions were $\mathrm{Ti}(8 \mathrm{~g}):(0.231,0.904,0.250)$, $\mathrm{Ti}(4 \mathrm{c}):(0,0.636,0.250), \mathrm{Sn}(4 \mathrm{c}):(0,0.163,0.250)$, as listed in Table 1 . Comparing the orthorhombic lattice parameters of $a, b$ and $c$ obtained from SAED and XRD, the differences were reasonable and within $5 \%$ measurement error of SAED. 


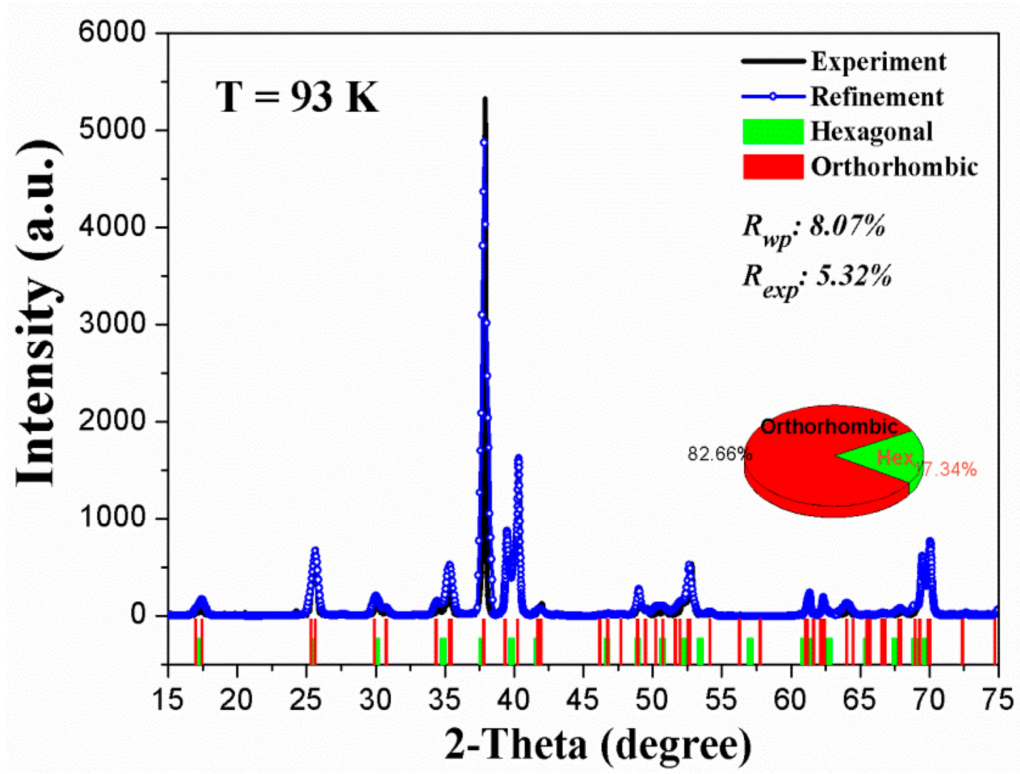

Figure 6. Rietveld refinement result of XRD profile of $\mathrm{Ti}_{3} \mathrm{Sn}$ powder at $93 \mathrm{~K}$, in which the hexagonal phase and the orthorhombic phase positions were indicated by green bars and red bars, respectively. The phase contents were also shown by the pie sub-figure as inserted.

Table 1. Crystallographic details of the new phase of $\mathrm{Ti}_{3} \mathrm{Sn}$.

\begin{tabular}{|c|c|c|c|c|}
\hline \multicolumn{5}{|c|}{ Phase: Orthorhombic } \\
\hline \multicolumn{5}{|c|}{ Space Group: Cmcm (No. 63). 16 Atoms Per Unit Cell } \\
\hline Lattice Parameters & & f Position & & \\
\hline 1 & \multirow{4}{*}{$\begin{array}{l}\mathrm{Ti}(8 \mathrm{~g}) \\
\mathrm{Ti}(4 \mathrm{c}) \\
\mathrm{Sn}(4 \mathrm{c})\end{array}$} & \multirow{4}{*}{$\begin{array}{l}\mathrm{x}: 0.231 \\
\mathrm{x}: 0 \\
\mathrm{x}: 0\end{array}$} & \multirow{4}{*}{$\begin{array}{c}\text { y: } 0.904 \\
y: 0.636 \\
y: 0.163\end{array}$} & \multirow{4}{*}{$\begin{array}{c}\text { z: } 0.250 \\
\text { z: } 0.250 \\
\text { z: } 0.250\end{array}$} \\
\hline $\mathrm{b}=10.37 \AA$ & & & & \\
\hline $\mathrm{c}=4.76 \AA$ & & & & \\
\hline$\alpha=\beta=\gamma=90^{\circ}$ & & & & \\
\hline
\end{tabular}

Temperature-dependent lattice parameters of $\mathrm{a}, \mathrm{b}$ and $\mathrm{c}$ for orthorhombic $\mathrm{Ti}_{3} \mathrm{Sn}$ obtained from XRD profiles were shown in Figure 7. It could be seen that parameter a reduced during cooling, parameter $\mathrm{c}$ remains almost constant, and parameter $\mathrm{b}$ increased during cooling. The $\mathrm{d}$-spacing of (hkl) plane in orthorhombic phase is calculated according to Equation (2):

$$
\mathrm{d}_{\mathrm{hkl}}=\frac{1}{\sqrt{\left(\frac{\mathrm{h}}{\mathrm{a}}\right)^{2}+\left(\frac{\mathrm{k}}{\mathrm{b}}\right)^{2}+\left(\frac{1}{\mathrm{c}}\right)^{2}}}
$$

Thus, when $\mathrm{D}_{19}$ plane (201) was divided into the doublet of orthorhombic (041) and (221) planes during cooling as indicated in Figure 2b, d-spacing of (041) should increase as lattice parameter b increases and c keeps constant, and d-spacing of (221) should decrease as the reduction of a is larger than the increment of $b$ during cooling, which are consistent with the results shown in Figure 4c.

Furthermore, comparing the projection drawings of hexagonal structure and orthorhombic structure of $\mathrm{Ti}_{3} \mathrm{Sn}$ from the $c$ axis as shown in Figure 8, the orthorhombic phase drawn in pink could be viewed as a distorted hexagonal phase with the main distortion in the ab plane since $\mathrm{a}_{\text {orthorhombic }} \approx \mathrm{a}_{\text {hexagonal, }} \mathrm{b}_{\text {orthorhombic }} \approx \sqrt{ } 3 \mathrm{~b}_{\text {hexagonal, }}$ corthorhombic $\approx$ chexagonal $_{\text {. Thus, the orientation }}$ relations between hexagonal parent phase and orthorhombic phase of $\mathrm{Ti}_{3} \mathrm{Sn}$ could be suggested as: (110) orthorhombic $/(100)_{\text {hexagonal }},<001>_{\text {orthorhombic }} / /<001>_{\text {hexagonal }}$. 


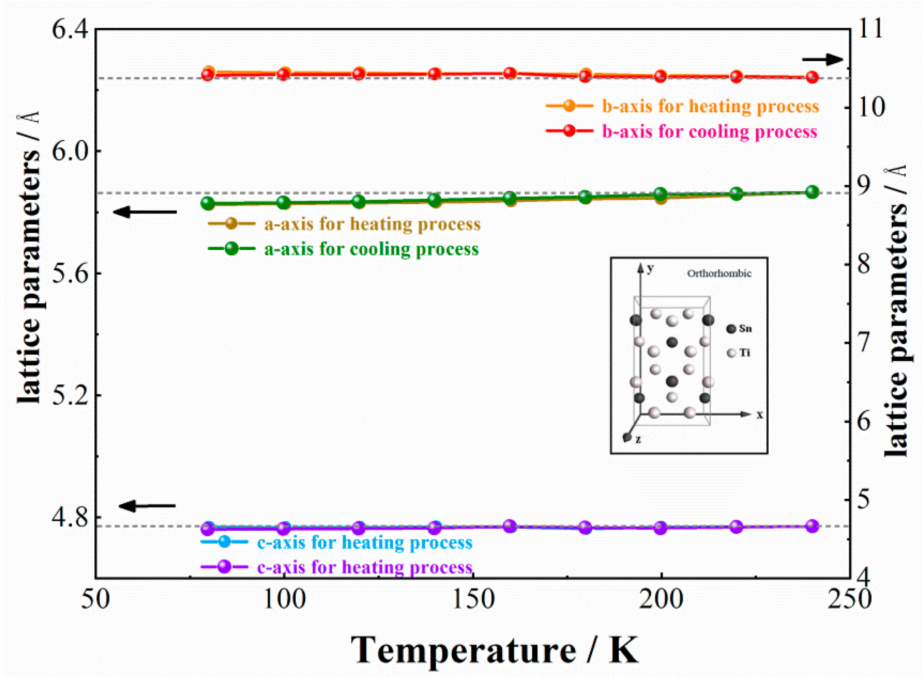

Figure 7. Temperature dependence of lattice parameters $\mathrm{a}, \mathrm{b}$ and $\mathrm{c}$ of orthorhombic $\mathrm{Ti}_{3} \mathrm{Sn}$ during cooling and heating processes, in which the schematic unit cell is also showed.

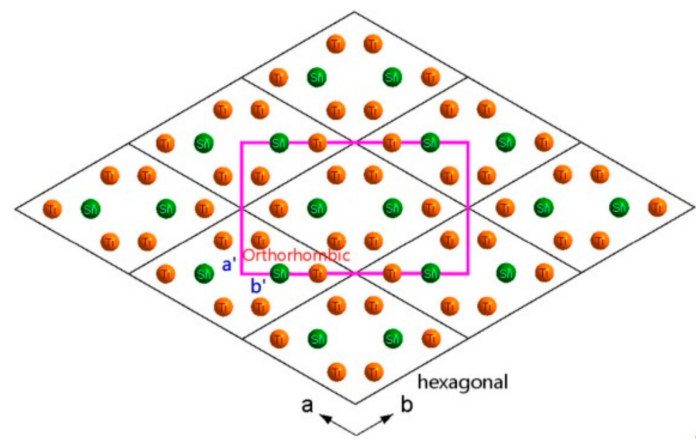

Figure 8. Comparison of the projection drawings of the hexagonal structure (drawn in black) and the orthorhombic structure (drawn in pink) of $\mathrm{Ti}_{3} \mathrm{Sn}$ from $\mathrm{c}$ axis, in which $\mathrm{a}, \mathrm{b}$ axes of the hexagonal structure and $\mathrm{a}^{\prime}, \mathrm{b}^{\prime}$ axes of the orthorhombic structure were also indicated.

\subsection{Discussion on the Thermodynamic Possibility of Phase Transformation}

Formation enthalpies of both hexagonal phase $\left(\mathrm{Ti}_{6} \mathrm{Sn}_{2}\right)$ and orthorhombic phase $\left(\mathrm{Ti}_{12} \mathrm{Sn}_{4}\right)$ of $\mathrm{Ti}_{3} \mathrm{Sn}$ were calculated using Equation (2). Considering the sole outer electrons of atom, for hexagonal $\mathrm{Ti}_{3} \mathrm{Sn}$ $\left(\mathrm{Ti}_{6} \mathrm{Sn}_{2}\right)$ on the basis of $\mathrm{E}\left(\mathrm{Ti}_{6} \mathrm{Sn}_{2}\right)=-7.073 \mathrm{eV}, \mathrm{E}(\mathrm{Ti})=-7.763 \mathrm{eV}, \mathrm{E}(\mathrm{Sn})=-3.835 \mathrm{eV}$, the formation enthalpy of hexagonal phase $\Delta \mathrm{H}\left(\mathrm{Ti}_{6} \mathrm{Sn}_{2}\right)$ is $-28.182 \mathrm{KJ} \mathrm{mol}^{-1}$ atom ${ }^{-1}$; for orthorhombic $\mathrm{Ti}_{3} \mathrm{Sn}\left(\mathrm{Ti}_{12} \mathrm{Sn}_{4}\right)$ on the basis of $\mathrm{E}\left(\mathrm{Ti}_{12} \mathrm{Sn}_{4}\right)=-7.078 \mathrm{eV}, \mathrm{E}(\mathrm{Ti})=-7.763 \mathrm{eV}, \mathrm{E}(\mathrm{Sn})=-3.835 \mathrm{eV}$, the formation enthalpy of orthorhombic phase $\Delta \mathrm{H}\left(\mathrm{Ti}_{12} \mathrm{Sn}_{4}\right)$ is $-28.654 \mathrm{KJ} \mathrm{mol}^{-1} \mathrm{atom}^{-1}$. Also, when considering all the electrons of atom, $\mathrm{E}\left(\mathrm{Ti}_{6} \mathrm{Sn}_{2}\right)=-7.219 \mathrm{eV}, \mathrm{E}\left(\mathrm{Ti}_{12} \mathrm{Sn}_{4}\right)=-7.223 \mathrm{eV}, \mathrm{E}(\mathrm{Ti})=-7.891 \mathrm{eV}, \mathrm{E}(\mathrm{Sn})=-4.008 \mathrm{eV}$, so the $\Delta \mathrm{H}$ $\left(\mathrm{Ti}_{6} \mathrm{Sn}_{2}\right)$ is $-28.848 \mathrm{KJ} \mathrm{mol}^{-1}$ atom ${ }^{-1}, \Delta \mathrm{H}\left(\mathrm{Ti}_{12} \mathrm{Sn}_{4}\right)$ is $-29.170 \mathrm{KJ} \mathrm{mol}^{-1}$ atom $^{-1}$. Therefore, according to the results of the two kinds of calculations above, both hexagonal phase and orthorhombic phase of $\mathrm{Ti}_{3} \mathrm{Sn}$ are stable phases, and $\Delta \mathrm{H}\left(\mathrm{Ti}_{12} \mathrm{Sn}_{4}\right)$ is more negative than $\Delta \mathrm{H}\left(\mathrm{Ti}_{6} \mathrm{Sn}_{2}\right)$, which indicates that the orthorhombic phase is more stable than the hexagonal phase, and the phase transformation from hexagonal phase to orthorhombic phase is reasonable according to thermodynamics theory.

\section{Conclusions}

The following conclusions can be drawn from this work:

i. The reversible thermal induced phase transformation of $\mathrm{Ti}_{3} \mathrm{Sn}$ is demonstrated by the means of $\mathrm{XRD}$ and thermal expansion experiment; 
ii. The temperature of forward phase transformation during cooling is $270-300 \mathrm{~K}$, and this phase transformation is reversible with a hysteresis of $10-30 \mathrm{~K}$ according to XRD results;

iii. The phase transformation is determined to be a hexagonal $\rightarrow$ orthorhombic transition, the lattice parameters of the new orthorhombic phase are: $a=5.87 \AA, b=10.37 \AA, c=4.76 \AA$ respectively, $\alpha=\beta=\gamma=90^{\circ}$, the space group is Cmcm (No. 63). The atomic Wyckoff positions for orthorhombic $\mathrm{Ti}_{3} \mathrm{Sn}$ are also provided;

iv. The orientation relationships between orthorhombic and hexagonal phases are suggested as: $(110)_{\text {orthorhombic }} / /(100)_{\text {hexagonal }},<001>_{\text {orthorhombic }} / /<001>_{\text {hexagonal }}$;

v. The hexagonal $\rightarrow$ orthorhombic phase transformation is calculated to be reasonable according to thermodynamics theory.

These findings contribute to a growing knowledge of intermetallic $\mathrm{Ti}_{3} \mathrm{Sn}$, and more comprehensive understanding of the formation mechanism of the orthorhombic phase is expected to be done in the future.

Author Contributions: Conceptualization, M.D. and L.C.; Methodology, M.D. and F.L.; Formal Analysis, M.D.; Investigation, M.D.; Writing—Original Draft Preparation, M.D.; Writing—Review \& Editing, M.D.; Supervision, L.C.; Project Administration, L.C.; Funding Acquisition, L.C. and F.L.

Funding: This study was funded by the National Natural Science Foundation of China (General Program: 51701159; Key Program: 51731010, 51431008; Major Project: 51790481) and the Fundamental Research Funds for the Central Universities (3102018zy007).

Conflicts of Interest: The authors declare no conflict of interest.

\section{References}

1. Yang, R.; Gu, Y.; Li, Y.; Zheng, J.; Li, X. Self-assembled 3-D flower-shaped $\mathrm{SnO}_{2}$ nanostructures with improved electrochemical performance for lithium storage. Acta Mater. 2010, 58, 866. [CrossRef]

2. Derrien, G.; Hassoun, J.; Panero, S.; Scrosati, B. Nanostructured Sn-C composite as an advanced anode material in high-performance Lithium-ion batteries. Adv. Mater. 2007, 19, 2336. [CrossRef]

3. Sougrati, M.T.; Fullenwarth, J.; Debenedetti, A.; Fraisse, B.; Jumas, J.C.; Monconduit, L. TiSnSb a new efficient negative electrode for Li-ion batteries: mechanism investigations by operando-XRD and Mössbauer techniques. J. Mater. Chem. 2011, 21, 10069. [CrossRef]

4. Wolfenstine, J.; Campos, S.; Foster, D.; Read, J.; Behl, W.K. Nano-scale $\mathrm{Cu}_{6} \mathrm{Sn}_{5}$ anodes. J. Power Sources 2002, 109, 230. [CrossRef]

5. Jacobs, J.K.; Dasgupta, S. Negative Electrode for a Rechargeable Lithium Battery Comprising a Solid Solution of Titanium Dioxide and Tin Dioxide. U.S. Patent Application No. 6,007,945, 28 December 1999.

6. Todd, A.D.W.; Mar, R.E.; Dahn, J.R. Combinatorial study of tin-transition metal alloys as negative electrodes for lithium-ion batteries. J. Electrochem. Soc. 2006, 153, 1998. [CrossRef]

7. Vdovychenko, O.V.; Bulanova, M.V.; Fartushna, Y.u.V.; Shcheresky, A.A. Dynamic mechanical behavior of intermetallic Ti 3 Sn. Scr. Mater. 2010, 62, 761. [CrossRef]

8. Zhang, J.; Perez, R.J.; Lavernia, E.J. Documentation of damping capacity of metallic, ceramic and metal-matrix composite materials. J. Mater. Sci. 1993, 28, 2399. [CrossRef]

9. Yin, F.; Tedenac, J.C.; Gascoin, F. Thermodynamic modeling of the Ti-Sn system and calculation of the Co-Ti-Sn system. Calphad 2007, 31, 370. [CrossRef]

10. Cech, R.G. Trans. vidence of solidification of a metastable phase in Fe-Ni alloys. AIME 1956, 206, 585.

11. Colin, M.C.; Denise, S.M.; Carlos, G.L. Phase selection in undercooled Ti 3 Sn. Metall. Trans. A 1993, 24, 1481.

12. Ivanova, O.; Karpets, M.; Yavari, A.R.; Georgarakis, K.; Podrezov, Y. In situ X-ray diffraction study of the phase transformation in the non-stoichiometric intermetallic compound Ti 3 Sn. J. Alloy. Compd. 2014, 582, 360. [CrossRef]

13. Aricò, A.S.; Bruce, P.; Scrosati, B.; Tarascon Jean-Marie Schalkwijk, W.V. Nanostructured materials for advanced energy conversion and storage devices. Nat. Mater. 2005, 4, 367. [CrossRef] [PubMed]

14. Fransson, L.M.L.; Vaughey, J.T.; Benedek, R.; Edström, K.; Thomas, J.O.; Thackeray, M.M. Phase transitions in lithiated $\mathrm{Cu}_{2} \mathrm{Sb}$ anodes for lithium batteries: an in situ X-ray diffraction study. Electrochem. Commun. 2001, 3, 317. [CrossRef] 
15. Kresse, G.; Furthmüller, J. Efficiency of ab-initio total energy calculations for metals and semiconductors using a plane-wave basis set. Comput. Mater. Sci. 1996, 6, 15. [CrossRef]

16. Kresse, G.; Furthmüller, J. Efficient iterative schemes for ab initio total-energy calculations using a plane-wave basis set. Phys. Rev. B 1996, 54, 11169. [CrossRef] [PubMed]

17. Kresse, G.; Hafner, J. Ab initio molecular dynamics for liquid metals. Phys. Rev. B 1993, 47, 558. [CrossRef]

18. Wolverton, C.; Ozoliš, V. First-principles aluminum database: Energetics of binary $\mathrm{Al}$ alloys and compounds. Phys. Rev. B 2006, 73, 144104. [CrossRef]

19. Liu, Z.; Chen, J.; Wang, S.B.; Yuan, D.W.; Yin, M.J.; Wu, C.L. The structure and the propeties of S-phase in AlCuMg alloys. Acta Mater. 2011, 59, 7396. [CrossRef]

20. Wong, C.R.; Fleischer, R.L. Low frequency damping and ultrasonic attenuation in $\mathrm{Ti}_{3}$ Sn-based alloys. J. Mater. Res. 1994, 9, 1441. [CrossRef]

21. Miller, W.; Smith, C.W.; Mackenzie, D.S.; Evans, K.E. Negative thermal expansion: A review. J. Mater. Sci. 2009, 44, 5441. [CrossRef]

22. Grima, J.N.; Zammit, V.; Gatt, R. Negative thermal expansion. Xjenza 2006, 11, 17.

23. Hahn, T. International Tables for Crystallography; Dordrecht Reidel: Dordrecht, The Netherlands, $1992 ;$ p. 41.

24. Lábár, J.L. Consistent indexing of a (set of) single crystal SAED pattern(s) with the ProcessDiffraction program. Ultramicroscopy 2005, 103, 237. [CrossRef] [PubMed]

(C) 2019 by the authors. Licensee MDPI, Basel, Switzerland. This article is an open access article distributed under the terms and conditions of the Creative Commons Attribution (CC BY) license (http://creativecommons.org/licenses/by/4.0/). 